\title{
TEMPORAL GRADATION AND TEMPORAL LIMITATION
}

\author{
FREDERIK KORTLANDT
}

In his magnum opus (Syntax and Semantics, Leiden 1978, henceforth: S\&S) C.L. Ebeling makes a distinction between temporal gradation (pp 301-308 and 337339) and temporal limitation ( pp 311-315). In the case of temporal gradation " $p$, q", the meaning " $q$ " specifies the time during which the referent carries the meaning "p". Example:

(1) Dutch jong knappe vrouwen "women who are / were pretty when they are / were young":

“...woman . PLUR . pretty, young...” (S\&S 338).

The time at which the women are/were pretty is specified by the time of their being young. Though nothing is said about the women at the time when they are no longer young, the phrase suggests that they may no longer be pretty. Similarly:

(2) Dutch hij is dronken gevaarlijk "he is dangerous when he is drunk":

$$
\begin{aligned}
& \text { "... } \sum \\
& \text { he }=\text { dangerous , drunk..." }
\end{aligned}
$$

The sentence suggests that he is not dangerous when he is not drunk because the situation where he is dangerous is included in the time when he is drunk. In the case of temporal limitation " $\mathrm{p} \sim \mathrm{q}$ ", the speaker opposes the referent as a carrier of the meaning " $p$ " to itself in situations where it does not carry the meaning " $q$ ". Example:

(3) Peter reading (written under a photograph):

$$
\text { “...PNPeter } \sim \text { [reading]...” (S\&S 313). }
$$

This phrase pictures Peter at the time when he is reading in contrast with a situation where he is not reading. The time during which the referent carries the name Peter is not included in the time when he is reading.

It must be asked whether the distinction between temporal gradation and temporal limitation is a clear-cut one. In a nexus layer not directly dominated by " $\Sigma$ " the difference is so slight that Ebeling eliminates it by a rule of descriptive hierarchy. Example: 
(4) she ate her soup cold: “... $\Sigma$

$$
\begin{aligned}
\text { she } & =[\text { eating }] \\
\text { soup } & =[\text { eaten }], \text { cold...", }
\end{aligned}
$$

for which the competing analysis with "...soup $\sim$ cold $=$ [eaten]..." is rejected (S\&S 315). The meaning is rewritten as

$$
\begin{aligned}
& \text { "... } \sum \\
& \text { she }=\text { [eating] } \\
& \quad \text { [eaten] , cold ; soup..." }
\end{aligned}
$$

at a later stage of the procedure.

The problem is more general, however. The relations " $p, q$ " and " $p \sim q$ " are in complementary distribution in Ebeling's analysis. The symbol for temporal gradation is used if " $p$ " is either a temporal nexus member (S\&S 324), or the second member in a relation of ordered limitation, or a situation " $\sum$ ", i.e. whenever " $p$ " can be viewed as the projection of a (set of) feature(s), not of an entity. The symbol for temporal limitation is used if " $p$ " is either a projection of an entity which carries a (set of) feature(s), or a pro-seme " $X$ ", which stands for a projection of an entity for which no features are specified except those which can be inferred from its position. The difference is only in part analogous to the one between nontemporal gradation and limitation, as is clear from the following example:

$$
\begin{aligned}
& \text { Dutch een luide schreeuwer "a loud bawler": } \\
& \text { “...<bawler> loud..." (cf. S\&S 213). }
\end{aligned}
$$

The referent of this phrase carries the meaning "loud" indirectly because the latter is the projection of a feature which characterizes the bawling. The loudness characterizes the referent only as a bawler.

Since the relations of temporal gradation and temporal limitation are in complementary distribution, the distinction can be eliminated. We can write " $\mathrm{p}, \mathrm{q}$ " for the generalized relation, which is defined in such a way that it limits the appropriateness of the referent as a carrier of the meaning " $p$ " to the time during which it carries the meaning "q" directly. If " $p$ " is a projection of an entity, the fact that the appropriateness of the referent is limited to the time when it carries the meaning "q" creates the opposition to a situation where it carries the meaning " $p$ " but not "q". If " $p$ " is the projection of a (set of) feature(s), the fact that the appropriateness of the referent is limited to the time when it carries the meaning "q" suggests that the referent does not carry the meaning " $p$ " when it does not carry the meaning "q". Thus, temporal gradation and temporal limitation are variants, the choice between them being determined by the semiotactic context.

I am not in favour of this solution because it leads to a cumbersome notation in a number of instances. Consider the following Dutch examples, which are analyzed in accordance with S\&S 354. 
(6) dronken is hij de president "when drunk, he is the president":

$$
\text { he } \sim \text { drunk }=\text { president..." }
$$

(7) hij is dronken de president "he is the president when he is drunk":

$$
\begin{aligned}
& \text { "... } \sum \\
& \text { he }=\text { president , drunk..." }
\end{aligned}
$$

(8) hij is de dronken president "he is the drunk president":

“... $\sum$

he $=$ president. drunk...”

The notation "...president . drunk..." is rewritten as "...president - drunk..." at a later stage of the procedure.

(9) hij is de president dronken "he is the president when he (= the president) is drunk" (e.g. about somebody doing an act at a party).

The following analysis of the last sentence seems to be intuitively satisfactory:

$$
\begin{aligned}
& \text { “.. } \sum \\
& \text { he }=\text { president } \sim \text { drunk..." }
\end{aligned}
$$

This notation violates the convention discussed above, however. It can be avoided by the introduction of a pro-seme. Compare in this connection Ebeling's analysis of the Russian instrumental case in the following instances (S\&S 313f):

(10) Mikkola byl professorom v Xel'sinki "Mikkola was a professor in Helsinki":

$$
\text { “... } \sum
$$

PNMikkola $=\mathrm{X} \sim$ professor..."

(11) Mikkola byl professor $v$ Xel'sinki (id.):

$$
\text { “... } \sum
$$

PNMikkola $=$ professor..."

(12) on vernulsja ustalym "he came home tired":

$$
\begin{aligned}
& \text { “.. } \sum \\
& \text { he }=\text { returning }, X \sim \text { tired..." }
\end{aligned}
$$

(13) on vernulsja ustalyj (id.):

$$
\begin{aligned}
& \text { “.. } \sum \\
& \text { he }=\text { returning , tired..." }
\end{aligned}
$$

(14) on vernulsja professorom "he returned as a professor":

$$
\begin{aligned}
& \text { “.. } \sum \\
& \text { he }=\text { returning, professor..." }
\end{aligned}
$$


In the last example Ebeling assumes temporal gradation because he regards temporal limitation as a marked construction and the instrumental case cannot be replaced with the nominative in the last sentence. This notation is not supported by the formal analogy with the other examples.

The crucial point is the analysis of sentence (12). Ebeling's notation suggests that the relation between the meanings "he" and "tired" is characterized by a three-step temporal connection. Two of these steps are present in the meaning of sentence (10), which can be paraphrased as follows: Mikkola was a professor in Helsinki at a given time, and the professorship distinguishes a period of Mikkola's life from other periods (cf. S\&S 313). Two steps are present in the meaning of sentence (13), which is approximately the following: he returned at a certain point of time, and he was tired at that time. The analysis of sentence (12) stands for: he returned at a certain time, and then he was tired, which he was not at some other time.

One may wonder if the notations for (12) and (13) do not contain any superfluous elements. The temporal nexus member "returning" specifies the time at which "he" is in the picture. The addition of ustalyj in example (13) does not seem to add any temporal specification other than the one which is already implied in the nexus relation. We can therefore consider the possibility that "tired" is linked to the preceding meaning by simple ordered limitation:

$$
\begin{aligned}
& \text { "... } \sum \\
& \text { he }=\text { returning - tired..." }
\end{aligned}
$$

Similarly:

(15) on sidit spokojnyj "he is sitting quietly":

$$
\begin{aligned}
& \text { “... } \sum \\
& \text { he }=\text { sitting, quiet..." (S\&S 338), }
\end{aligned}
$$

where we can suggest:

$$
\begin{aligned}
& \text { “.. } \sum \\
& \text { he }=\text { sitting - quiet..." }
\end{aligned}
$$

The meaning "quiet" does not seem to involve an independent temporal specification. The following example offers counter-evidence against this interpretation:

(16) èto ja malen'kij "that is me when I was small" (while showing a photograph).

In this sentence, the meaning "small" is obviously connected with the preceding by a temporal relation. It does not seem justified to ascribe different semiotactic structures to (13) and (15) on the one hand, and to (16) on the other. Thus, I uphold Ebeling's analysis of sentences (13) and (15). 
In example (16), it does not seem possible to replace the nominative case with the instrumental. Both possibilities are acceptable in the following instances, however:

(17) èto Valja malen'kaja "that is Valja when she was small",

(18) èto Valja malen'koj (id.).

Compare in this connection:

(19) vot zdes' ja malen 'kij "this is me when I was small":

"... $\sum$

me $=$ small..."

(20) vot zdes' ja malen'kim (id.)

"... $\sum$

me $\sim$ small..."

An intuitively satisfactory analysis of (18) seems to be the following:

$$
\begin{aligned}
& \text { “.. } \sum \\
& \text { that }=\text { PNValja } \sim \text { small..." }
\end{aligned}
$$

This notation, like the one under (9) above, violates the convention under discussion.

We can maintain the complementary distribution of temporal gradation and temporal limitation by the introduction of a pro-seme. Thus, we can analyze (18) in the same way as (12) above:

$$
\begin{aligned}
& \text { "... } \sum \\
& \text { that }=\text { PNValja }, \mathrm{X} \sim \text { small..." }
\end{aligned}
$$

This notation is not intuitively satisfactory, however. It stands for: that was Valja at a time which is specified by the circumstance that she was in a period of her life when she was small. I think that the temporal gradation is superfluous in this notation and that it must preferably be eliminated. The simplified notation reads: that was Valja at a time when she was small, in contrast with other periods of her life. Similarly, we can simplify the analysis of example (12):

$$
\begin{aligned}
& \text { “.. } \sum \\
& \text { he }=\text { returning } \sim \text { tired..." }
\end{aligned}
$$

This notation stands for: he returned at a time when he was tired, which he was not at some other time. Of course, the complementary distribution of temporal gradation and temporal limitation is given up if this notation is accepted, and the latter relation ceases to be a marked construction. 
If the relations of temporal gradation and temporal limitation are no longer in complementary distribution, it must be investigated whether it is expedient to interpret certain instances of temporal gradation as cases of temporal limitation. In example (4), there is no reason to replace the analysis given above because the sentence suggests that the soup was not eaten when it was not cold. Similarly:

(21) she likes tulips yellow:

$$
\begin{aligned}
\text { “... } & \sum \\
\text { she } & =[\text { liking }] \\
\text { tulips } & =[\text { liked }], \text { yellow..." (S\&S 305), }
\end{aligned}
$$

which is rewritten as

$$
\begin{aligned}
& \text { "... } \sum \\
& \text { she }=[\text { [liking }] \\
& \quad \text { [liked] , yellow ; tulips..." }
\end{aligned}
$$

at a later stage. This sentence suggests that she does not like tulips which are not yellow, or at least prefers them to be yellow. On the other hand, sentence (14) does not suggest that he would not come back if he had not been a professor; it rather means that he happened to be a professor when he came back, in contrast with an earlier period of his life. The following notation therefore seems to be preferable:

$$
\begin{aligned}
& \text { “.. } \sum \\
& \text { he }=\text { returning } \sim \text { professor..." }
\end{aligned}
$$

This notation is moreover in accordance with the formal analogy between examples (12) and (14).

We can now put forward the hypothesis that the Russian instrumental case denotes a relation of temporal limitation whenever it does not either simply fill a slot or embody an independent semantic particle. Consider the following examples:

(22) on el rebenkom ikru "he ate caviar as a child":

$$
\begin{aligned}
& \text { "... } \sum \\
& \text { he }=\text { [eating] , child } \\
& \quad \text { [eaten] ; caviar..." }
\end{aligned}
$$

(23) on el pudami ikru "he ate caviar in large quantities":

$$
\begin{aligned}
& \text { “... } \sum \\
& \text { he }=\text { [eating] } \\
& \quad \text { [eaten], poods ; caviar..." }
\end{aligned}
$$

In these examples, which are taken from an unpublished paper by Ebeling, I would prefer to substitute 


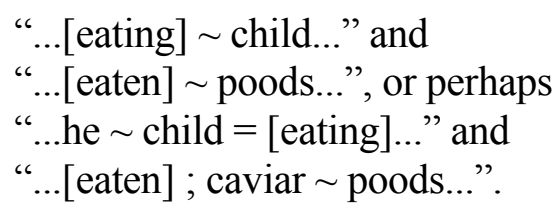

Sentence (22) does not suggest that he stopped eating caviar when he grew up, but rather that he ate caviar when he still was a child. Sentence (23) does not suggest that he did not eat caviar unless it was offered to him in large quantities, but rather that he had a lot of caviar to eat. Thus, the symbol for temporal limitation seems to be more appropriate than the symbol for temporal gradation. Compare in this connection the Russian translation of example (21):

ona ljubit tjul'pany želtye.

If we replace želtye with the instrumental želtymi, one gets the impression that the tulips have been painted:

(25) ona ljubit tjul'pany želtymi "she likes tulips yellow":

$$
\begin{aligned}
\text { “.. } & \sum \\
\text { she } & =[\text { liking }] \\
\text { tulips } & =[\text { liked }] \sim \text { yellow..." }
\end{aligned}
$$

which can be rewritten either

“...[liked] yellow ; tulips..." or, preferably,

“...[liked]; tulips yellow...".

A natural example of this interpretation is the following:

(26) ona ljubit derev'ja želtymi "she likes the trees yellow", with reference to trees which change their colour according to the season.

It is possible to take another step in the following instances:

(27) on el dorogoj ikru "he ate caviar on his way":

$$
\begin{aligned}
& \text { “... } \sum \\
& \downarrow \\
& \sim \operatorname{road} . . .
\end{aligned}
$$

(28) on el utrom ikru "he ate caviar in the morning":

$$
\begin{aligned}
\text { “... } \sum & \downarrow \\
& \sim \operatorname{morning} . . . "
\end{aligned}
$$

In these sentences, the instrumental case ending does not seem to carry a separate semantic particle: it simply expresses the temporal limitation of the situation. A less obvious example is the following: 
(29) on el ložkoj ikru "he ate caviar with a spoon":

“... $\sum$

he $=<$ [eating $]>\downarrow$

$\sim$ spoon

[eaten] ; caviar..."

If this analysis is acceptable, the instrumental case receives a uniform notation except for those instances where it simply fills a slot:

(30) on upravljaet mašinoj "he drives a car":

“... $\sum$

he $=[$ directing $]$

[directed] ; machine..."

There is no temporal characterization here. 